\title{
AN EVALUATION OF CLOVE (Eugenia caryophyllata) ESSENTIAL OIL AS A POTENTIAL ALTERNATTIVE ANTIFUNGAL WOOD PROTECTION SYSTEM FOR CULTURAL HERITAGE CONSERVATION
}

\author{
Dana-Mihaela Pop ${ }^{1}$ \\ https://orcid.org/0000-0002-5838-2975 \\ Maria Cristina Timar ${ }^{1, \$}$ \\ https://orcid.org/0000-0002-6118-5139 \\ Anca Maria Varodi ${ }^{1}$ \\ https://orcid.org/0000-0003-2706-7988 \\ Emanuela Carmen Beldean ${ }^{1}$ \\ https://orcid.org/0000-0002-5888-9151
}

\begin{abstract}
This paper investigates the potential of clove (Eugenia caryophyllata) essential oil (C-EO) as a wood protection system for use in cultural heritage conservation. The preventive and curative antifungal efficacy of C-EO was compared to a boron containing wood preservative (Diffusit S) in two laboratory tests on European beech (Fagus sylvatica) and Scots pine sapwood (Pinus sylvestris) mini-blocks. Non-sterile, air-infected wood samples were employed in the first test, while wood samples with active attack, as result of inoculation with three fungal strains isolated from cultural heritage sites, in the second test. Untreated controls and C-EO-treated wood blocks were incubated up to 150 days to monitor and quantify fungal growth. The experimental results showed antifungal efficacy of C-EO to be higher than that of the boron wood preservative at the concentrations used. Concentrations of C-EO $5 \%-10 \%$ in ethyl alcohol prevented mould growth for at least 150 days, while a concentration of $10 \%$ delayed or suppressed active attack by decay fungi. This effect, determined up to 90 days of incubation, was dependant on the type of fungus.
\end{abstract}

Keywords: Antifungal, clove, cultural heritage, essential oils, wood bioprotection.

\section{INTRODUCTION}

Biodeterioration by fungi represents a major risk factor for wood cultural heritage $(\mathrm{CH})$ (Sterflinger 2010, Alfieri et al. 2016, Sabatini et al. 2018, Lee et al. 2018) in any situation when the moisture content in wood is above the $20 \%$ threshold (Brischke and Alfredsen 2020, Eaton and Hale 1993, Broda 2020). This may be the case not only in outdoors but also in particular indoors situations when atmospheric relative humidity (RH) cannot be controlled and maintained under $55 \% \mathrm{RH}$, which is generally regarded as the threshold line for fungal growth in museums (Sterflinger 2010). Such conditions are often present inside the monuments in open air museums.

${ }^{1}$ Transilvania University of Brașov, Faculty of Furniture Design and Wood Engineering, Department of Wood Processing and Wood Products Design, Brașov, Romania.

•Corresponding author: cristinatimar@unitbv.ro

Received: 07.04.2021 Accepted: 18.11.2021 
A range of fungi are involved in wood colonisation and subsequent biodeterioration. Mould (Zygomycota or Ascomycetes) and staining fungi (Ascomycota and Deuteromycota) are usually the first colonisers; they disfigure wood without affecting wood strength, though wood permeability might be increased (Eaton and Hale 1993, Morris 2011, Lie et al. 2019a, Lie et al. 2019b, Broda 2020). In contrast, wood-decay fungi belonging to three major groups: brown rot (Basidiomycota), white-rot (Basidiomycota) and soft-rot (Ascomycota-fungi imperfecti) cause degradation of structural wood polymers via characteristic enzymatic and non-enzymatic processes, resulting in specific chemical changes and patterns of wood tissue degradation, visible at microscopic and macroscopic levels, and can result in significant loss of strength (Eaton and Hale 1993, Morris 2011, Broda 2020, Pandey and Pitman 2003, Brischke et al. 2014, Fackler et al. 2010, Fackler and Schwanninger 2012). Disfigurement by moulds, which can also be a source of mycotoxins affecting human health, and decay are a threat to wood cultural heritage (abbreviated $\mathrm{CH}$ ) and have to be prevented or cured. The best way of preventing fungal degradation of wood $\mathrm{CH}$, whenever possible, is controlling the environmental conditions to avoid wetting of wood (preventive or passive conservation), but, when this first option is not possible, biocides are employed for preventive and /or curative treatments (active conservation) (Kakakhel et al. 2019).

Advanced techniques and classical methods are currently widely employed to evaluate the diversity of microbial / fungal communities responsible for $\mathrm{CH}$ biodeterioration (Sabatini et al. 2018, Lee et al. 2018, Kim et al 2016, Adamiak et al. 2018, Zhang et al. 2019), while novel necessary developments look to alternative biocides effective against this attack. These include green biocides from natural resources, such as essential oils (EOs), (Kakakhel et al. 2019), which have been recognised as potential eco-friendly alternatives to conventional chemical preservatives due to their proven biocidal properties. Concerns related to conservators-restorers health (Varnai et al. 2011) are in favour of employment of EOs in CH conservation, as chemical treatments applied should be efficient while non-toxic and non-destructive (Stupar et al. 2014). Nevertheless, potential toxicity and safety issues related to EOs have to be thoroughly analysed (Lis-Balchin 2006).

Worldwide research has focussed on the antifungal potential/efficiency of several EOs from different vegetal resources, such as: clove (Eugenia caryophyllata), ajowan (Carum opticum), dill (Anethum graveolens), Egyptian geranium (Pelargonium graveolens), lemongrass (Cymbopogon flexuosus), rosemary (Rosmarinus officinalis), tea tree (Melaleuca alternifolia), thyme (Thymus zygis) birch (Betula pendula), lavender (Lavandula angustifolia), oregano (Origanum vulgare), sweet flag (Acorus calamus), savory (Satureja hortensis), sage (Salvia officinalis), against various types of fungi, including mould and decay fungi responsible for wood biodegradation (Yang and Clausen 2007, Zyani et al. 2011, Panek et al. 2014, Xie et al. 2017, Bahmani and Schmidt 2018, Broda 2020). The antifungal activity of EOs against wood degrading fungi has been associated to their complex chemical composition (Bakkali et al. 2008, Wang et al. 2005, Zhang et al. 2016), mainly to some of their majoritarian components, such as: carvacrol, thymol, eugenol and cinnamaldehyde (Xie et al. 2017). Clove essential oil (C-EO) extracted from Eugenia caryophyllata is one of the EOs showing potential for antifungal wood bioprotection due to its high content (67-78\%) in eugenol (Xie et al. 2017, Borrego et al. 2012). The antifungal properties of C-EO has been demonstrated by different types of tests, mostly screening tests on culture medium (Zyani et al. 2011, Panek et al. 2014, Xie et al. 2017, Reinprecht et al. 2019, Borrego et al. 2012), and less frequently tests on wood samples (e.g. Panek et al. 2014). Different fungal strains, including white rot (e.g. Trametes hirsuta, Trametes versicolor, Thielavia hyalocarpa), brown rot (e.g. Laetiporus sulphureus, Coniophora puteana, Cladosporium cladosporioides, Serpula lacrymans) and mould fungi (e.g. Aspergillus niger, Penicillium brevicompactum, Alternaria alternata, Chaetomium globosum), were employed in these tests.

Potential of various EOs, including C-EO, for applications in $\mathrm{CH}$ conservation, such as stone monuments, (Jeong et al. 2018), documentary heritage (Borrego et al. 2012, Pietrzaka et al. 2017), or textiles disinfection (Matusiak et al. 2018), has been reported in literature. However, when looking at wood CH conservation, literature references are rather scarce and they usually report on the efficiency of different EOs (including or not C-EO) against fungal strains isolated from $\mathrm{CH}$ sites, determined in vitro via mycological screening tests on culture media (Zyani et al. 2011, Stupar et al. 2014, Wu and Chou 2018).

Although screening tests on agar medium offer the advantage of a quick and simple method of assessing the fungicidal potential of new products, there are also some limitations and controversy related to their suitability for testing products for wood protection against decay fungi (Eaton and Hale 1993) and tests on impregnated wood (e.g. mini-block) should be employed for validation. Also, testing in conditions relevant for real applications is important.

Based on the literature reviewed in this paper, from 17 papers reporting antifungal efficiency of various EOs, only four report on antifungal efficiency of EO applied to wood samples (Panek et al. 2014, Reinprecht 
and Vidholdová 2017, Yang and Clausen 2007, Bahmani and Schmidt 2018) and even fewer considered in the testing protocol the potential application of EOs for wood $\mathrm{CH}$ conservation with some specific particularities, such as, for instance, natural air-borne fungal infection of wood (Bahmani and Schmidt 2018).

The present research aimed at testing the efficacy of C-EO in preventive and curative antifungal treatments as necessary and applied in wood conservation practice, considering some particular aspects of this field:

- both preventive and curative treatments against fungal attack (moulds, decay) might be necessary depending on the conservation state of the wood material and the environmental conditions it is exposed to;

- cultural heritage sites, as well as, conservation-restoration laboratories are likely to be rich in fungal spores including those of wood colonising fungi, which may cause airborne infection of new/sound wood material (Sterflinger 2010, Alfieri et al. 2016, Sabatini et al. 2018, Kim et al. 2016) and consequent risk of attack in wet conditions;

- in restoration, new wood employed for repair of decayed parts or completion of missing ones will frequently be in contact with viable spores or mycelium which under the right conditions may re-activate.

Accordingly, two types of mycological laboratory tests were designed and carried out, in order to compare the efficacy of C-EO against a boron-based biocide, considered as reference in this research: (1) on un-decayed (new) wood, naturally infected via airborne spores and (2) on wood part-decayed by rot fungi isolated from $\mathrm{CH}$. Both tests were based on a common principle: small samples of untreated (control) and treated wood were employed as inoculum on a sterile culture medium and emerging fungal development was monitored and evaluated.

\section{MATERIALS AND METHODS}

\section{Materials}

Clove (Eugenia caryophyllata) essential oil (C-EO), as a commercial product (100\%), available on the Romanian market under the label of "Steaua Divina", was employed in this research. It was diluted with ethyl alcohol (96\%) at volumetric ratios of 5:100 and 10:100, resulting two treatment solutions, referred to as C-EO $5 \%$ and C-EO $10 \%$ in this paper.

In our comparison, the reference product was Diffusit $\mathrm{S}$ (Wolman product), a boron based wood preservative, currently employed in wood conservation practice. Diffusit $\mathrm{S}$ was diluted to $5 \%$ and $10 \% \mathrm{w} / \mathrm{v}$ in water, concentrations which are commonly employed for preventive and curative treatments in wood conservation practice.

\section{Wood samples}

Planed blocks of $20 \mathrm{~mm} \times 20 \mathrm{~mm} \times 5 \mathrm{~mm}$ on the longitudinal, radial and tangential directions, respectively, were prepared of sound European beech (Fagus sylvatica) wood and Scots pine sapwood (Pinus sylvestris), usually employed in biological tests as non-durable references. The samples were processed, then stored, in the workshop and restoration laboratory atmosphere and were not sterilised before testing. Prior to treating and testing, all samples were conditioned at $20^{\circ} \mathrm{C}$ and $65 \% \mathrm{RH}$ in a Feutron climatic chamber to constant weight.

\section{Methods}

\section{Laboratory test 1-preventive treatment of new, air-infected wood}

This test focused on the efficiency of the tested products in preventing a fungal attack of new wood, considering its potential natural infection by airborne spores. Batches of 8 non-sterilised blocks of each wood species were treated, by immersing them for 2 hours (at $20^{\circ} \mathrm{C}$ ) in either the C-EO or Diffusit S solutions at $5 \%$, $10 \%$, while 8 blocks of each wood species were kept untreated as controls. Solutions uptakes for blocks were calculated by determination of difference in weight before and immediately after treatment. The samples were then re-conditioned in the climatic chamber until they reached a constant weight. Forty Petri dishes containing sterile malt extract/agar-agar culture medium (MEAA: $40 \mathrm{~g}$ malt extracts ROTH and $20 \mathrm{~g}$ agar-agar ROTH for 1 litre distilled water) were prepared. Two test samples were placed directly on the media in each Petri dish, 
resulting 4 Petri dishes for each variant. Immediately after placing the samples, the dishes were sealed with parafilm and incubated in a Climacell chamber at $22{ }^{\circ} \mathrm{C}$ and $70 \% \mathrm{RH}$. The microbial colonisation of blocks was examined after 50, 73, 100, 118, 142 and 150 days. After this period, the blocks were removed, cleaned of mycelium, sterilised and reconditioned.

\section{Laboratory test 2-curative treatment of decayed wood}

This test focused on the efficiency of the tested products in curative treatments against active attack by decay fungi. Decayed samples were prepared by inoculating blocks with three decay fungal strains from $\mathrm{CH}$ sites. These were previously isolated from degraded wood from historic buildings in Brașov old town or old furniture pieces, which presented clear macroscopic evidence of degradation by decay fungi. Isolation was achieved by the classical cultivation method on (MEA) culture medium, often applied for studying fungi from cultural heritage (e.g. Sterflinger 2010, Lee et al. 2018, Kim et al. 2016, Zhang et al. 2019, Stupar et al. 2014). The isolated fungi were coded FC1-W, FC1-B and S-W, considering the source of the degraded wood employed as inoculum for fungal isolation and some visible differentiating features of the mycelium growth during the isolation procedure by sub-culturing (Zhang et al. 2019, Alborés et al. 2018, Al-Jaradi et al. 2018).

Un-decayed European beech (Fagus sylvatica) and Scots pine sapwood (Pinus sylvestris) blocks (of dimensions described in the materials section) were exposed to the three fungal strains (2-3 blocks/species/ fungal strain) in Petri dishes (prepared with sterile MEAA culture medium), which were centrally inoculated with one of the strains. The Petri dishes were incubated for 140 days at $22{ }^{\circ} \mathrm{C}$ and $70 \% \mathrm{RH}$. After this period, the samples were removed and the fungal mycelium removed from the block surfaces.

After this step, one block of each wood species/fungal strain was kept as a degraded untreated control, while the others were sectioned into 2 or 3 smaller pieces for curative treatments with C-EO or Diffusit S solutions. Treatment was by total immersion of the decayed wood samples for 30 minutes at room temperature in the respective solutions (C-EO $10 \%$, Diffusit S $10 \%$ ). After removing the excess of the treating solution with blotting paper the samples were placed on freshly prepared, sterile MEAA culture medium (one sample/ dish) and re-incubated. For each wood species/fungal strain were prepared one control sample (degraded, not treated), two degraded samples treated with C-EO and two degraded samples treated with Diffusit S. The efficiency of the treatments applied was evaluated by monitoring fungal development after 7, 42 and 90 days. The samples were then removed, cleaned of mycelium, sterilised by heating and re-conditioned.

FTIR analyses (not presented in this paper) performed on the decayed controls following inoculation with the three isolated strains (FC1-B, FC1-W, S-W) and incubation highlighted chemical changes in wood structure affecting the main wood components. Based on the specific chemical changes revealed by FTIR, in accordance to literature (Pandey and Pitman 2003), it was concluded that the three strains were most likely $B a$ sidiomycete decay fungi as follows: FC1-B and FC1-W brown-rot fungi and $\mathrm{S}-\mathrm{W}$ a selective white-rot fungus.

\section{Digital quantification of fungal development and indices calculation}

A digital method to quantify the area of mycelium growth, based on ImageJ software (ImageJ databases, 2020) was developed and applied. The area covered by the mycelium was evaluated in relation to the whole area of the plate (Petri dish). A quantitative percentage indicator of fungal development, named fungal coverage area (FCA, \%), was calculated as follows (Equation 1):

$$
F C A=100 \times \frac{A_{m}}{A_{0}}(\%)
$$

where: $A_{m}$ - area covered by the mycelium; $A_{0}$ - whole area of the plate (Petri dish)

Based on the FCA values, absolute and relative indices of reduction of fungal development (IRD, \%) were calculated to highlight and compare the antifungal activity of the tested products (C-EO and the reference product), similarly to a previous publication of the authors (Pop et al. 2020) (Equation 2): 


$$
I R D-a b s=100 \times \frac{F C A_{\text {control }}-F C A_{\text {treated }}}{F C A_{\text {control }}}
$$

Where: $\mathrm{FCA}_{\text {control }}, \mathrm{FCA}_{\text {treated }}$ - represent the calculated fungal coverage area values for the untreated control samples and, respectively, the treated samples (Equation 3).

$$
I R D-r e l=100 \times \frac{F C A_{\text {reference }}-F C A_{C E-O}}{F C A_{\text {reference }}}
$$

Where: $\mathrm{FCA}_{\text {reference }}, \mathrm{FCA}_{\mathrm{C}-\mathrm{EO}}$ - represent the calculated fungal coverage area values for the samples treated with the reference product and, respectively, the samples treated with C-EO.

\section{RESULTS AND DISCUSSION}

\section{Laboratory test 1- preventive treatment of new, air-infected wood}

The results of this test are illustrated in Figure 1 (European beech) and Figure 2 (Scots pine), which compare images and FCA values of fungal development on untreated controls and the corresponding samples treated with Diffusit S and C-EO (solutions of 5 and $10 \%$ concentration).

Fungal growth, most likely moulds, on the control European beech and Scots pine sapwood blocks was evident after one week's incubation and evolved rapidly over time. A diversity of fungi covered the plates $(\mathrm{FCA}=100 \%)$ after 50 days for both European beech (Figure 1) and Scots pine (Figure 2). The types of fungi colonising plates differed for beech and pine blocks. This could be explained by the processing of blocks at different times. Also, some blue stain might have been present on the Scots pine sapwood samples and particularities in the susceptibility of different wood species to various fungi, both moulds and decay fungi, have to be considered (Eaton and Hale 1993, Morris 2011, Lie et al. 2019a, Lie et al. 2019b, Brischke et al. 2014, Reinprecht 2010).

This test on new wood samples demonstrated that viable fungal spores were present in the environment the blocks were processed and stored causing their natural air-infection. To prevent fungal growth it is important wood does not wet up and exceed $20 \%$ moisture content (MC) (Brischke and Alfredsen 2020), but when this condition can not be ensured preventive antifungal treatments should be considered.

These results are supported by literature data on the large variety and variability of airborne fungi in cultural heritage sites and the influence of air circulation, environmental factors, climatic conditions and seasons on the fungal community (Kim et al. 2016). Several studies on contamination of wood artworks from museums or other environments and evaluation of the microbial communities involved clearly showed the role of fungi in wood degradation and their great diversity (Sabatini et al. 2018, Zhang et al. 2019). Moreover, characteristic succession patterns or interactions and competition aspects should be considered in a dynamic process of wood fungal colonisation and degradation (Alfieri et al. 2016, Morris 2011, Jönsson et al. 2008, Ottosson et al. 2014, Hiscox et al. 2018, Ujor et al. 2018). Moulds grow very fast compared to wood decay fungi on MEA and it is very likely that this was more or less a test of mould inhibition (i.e. the mould could have outcompeated any basidiomycetes present). The aspect of the control samples after the test, with quite intense black surface discolouration but no other indication of degradation, support the idea that only mould fungi were activated in this test. This was confirmed by FTIR investigation of the control samples (not presented in this paper): proteins absorption bands associated to the fungal cellular content were present on the discoloured wood surfaces, whilst no chemical changes could be detected on their cleaned subsurfaces, which means that no decay fungi were active.

The treatment with the reference product Diffusit S, showed a different influence on the two wood species 
regardless of the concentration. In the case of European beech wood (Figure 1), fungal development was delayed for 2 weeks, though by 50 days the level of colonisation was similar to untreated blocks. In the case of Scots pine sapwood (Figure 2) the situation was different with no fungal development even at 150 days. This could be explained by differences in absorption between species, this being $255 \mathrm{~kg} / \mathrm{m}^{3}-330 \mathrm{~kg} / \mathrm{m}^{3}$ for Scots pine sapwood and $190 \mathrm{~kg} / \mathrm{m}^{3}-216 \mathrm{~kg} / \mathrm{m}^{3}$ for European beech. Higher uptakes were found using solutions at $5 \%$ concentration. Differences in the fungal communities developed on the two types of wood species and in their resistance / sensitivity to the boron-based preservative employed should also be considered. Literature indicates that boron compounds act primarily as inhibitors of enzymatic processes and fungal growth and that they act more as fungistatics rather than fungicides (Eaton and Hale 1993). Moreover, their antifungal efficiency depends on the type of fungi: boron compounds are more effective against wood decaying fungi than against moulds (Reinprecht 2010).

C-EO solutions seemed more efficient though differences were observed between the species. In the case of European beech fungal development was observed, on one plate from 4 replicates for C-EO $5 \%$, resulting an average FCA of $23,2 \%$, after 140 days of incubation. In the case of Scots pine sapwood, the treatment with C-EO $5 \%$ was very efficient, without any sign of fungal growth throughout the test (150 days). When C-EO was employed at $10 \%$ concentration, the treatment was effective for both European beech and Scots pine sapwood, without any fungal development $(\mathrm{FCA}=0 \%)$. In the treatment with $\mathrm{C}$-EO the absorption of solutions ranged from $155-165 \mathrm{~kg} / \mathrm{m}^{3}$ for Scots pine sapwood, and $206 \mathrm{~kg} / \mathrm{m}^{3}-209 \mathrm{~kg} / \mathrm{m}^{3}$ for European beech wood, which were lower, at least in the case of Scots pine sapwood, than for the Diffusit solutions. The efficacy of C-EO in preventing mould growth on wood was also demonstrated by previous studies (Reinprecht and Vidholdová 2017, Panek et al. 2014).

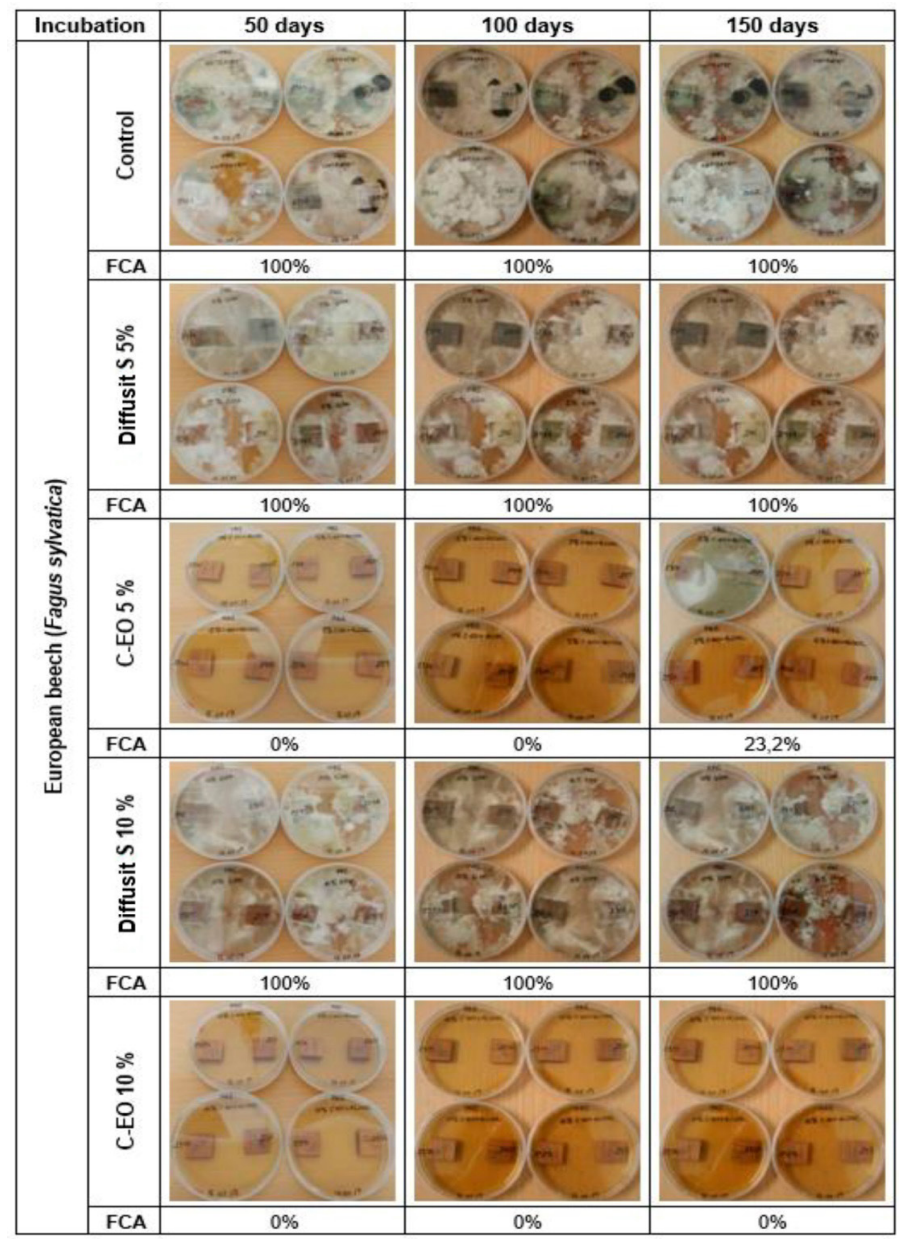

Figure 1: Lab test 1- European beech wood (Fagus sylvatica): influence of Diffusit S and C-EO solutions $(5,10 \%)$ on fungal development after 50,100 and 150 days incubation, as a result of natural/incidental infection of new sound wood in laboratory conditions; calculated fungal coverage area values (FCA, \%) included. 


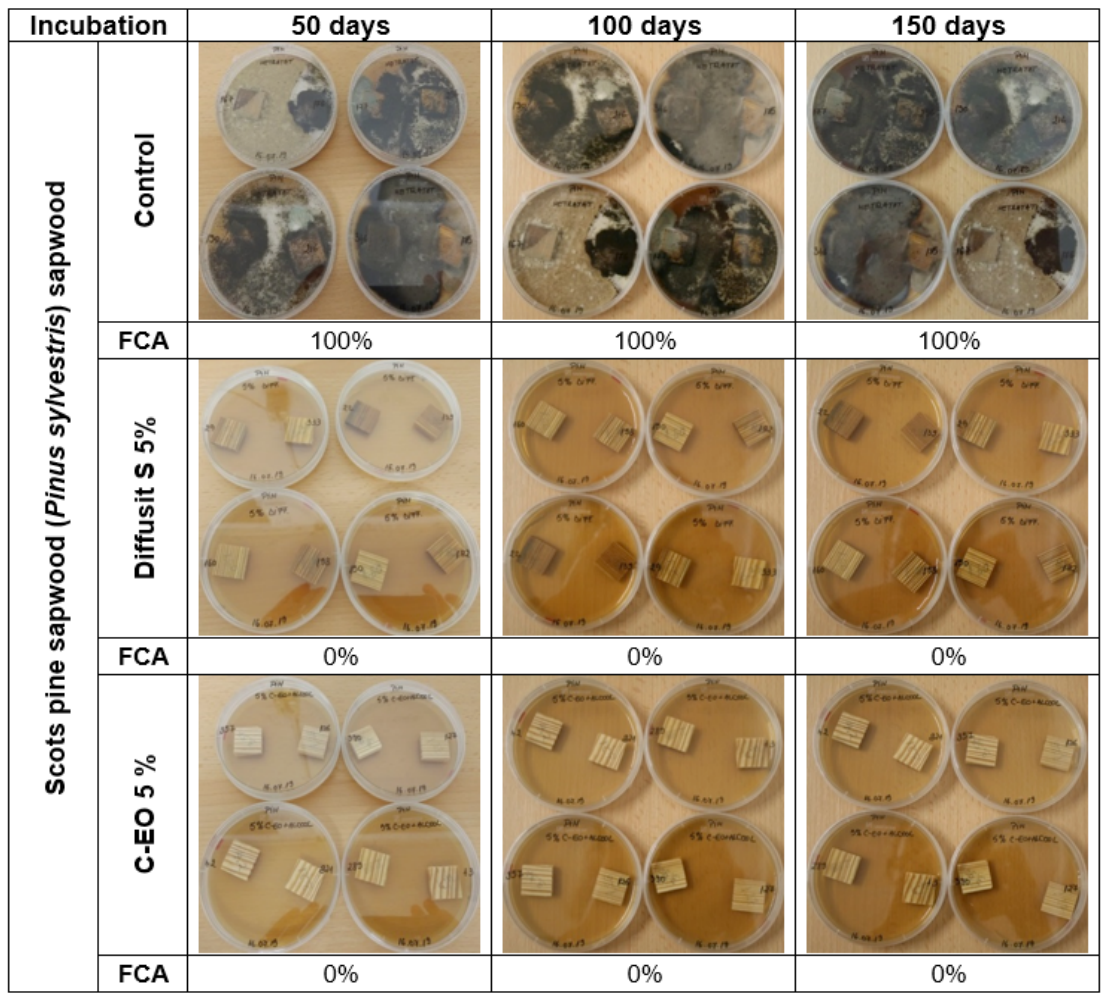

Figure 2: Lab test 1- Scots pine (Pinus sylvestris) sapwood: influence of Diffusit S and C-EO solutions (5 \%) on fungal development after 50, 100 and 150 days incubation, as result of natural/incidental infection of new sound wood in laboratory conditions; calculated fungal coverage area values (FCA, \%) included.

Data for European beech blocks suggests that C-EO was more efficient than Diffusit $\mathrm{S}$ in preventing growth of airborne mould fungi at retentions used. Alcoholic solutions of C-EO (5\% - $10 \%)$ should be employed for this purpose, in accordance to the risk of fungal infestation, the environmental conditions and the natural durability of the wood species. However, more research is needed to validate these results, including some ageing tests.

\section{Laboratory test 2-treatment against active attack by decay fungi}

The results of this test are illustrated in Figure 3, Figure 4 and Figure 5, which compare images and FCA values of fungal development on untreated decayed controls and the corresponding samples treated with Diffusit S and C-EO (solution of $10 \%$ concentration). The decayed control samples were prepared in the lab (section 2.2.2), by employing three decay fungal strains: FC1-W (brown-rot), FC1-B (brown-rot), S-W (selective white-rot) isolated from cultural heritage.

For all decayed control samples (Figure 3, Figure 5), fungal growth was evident after 7 days of incubation for both European beech and Scots pine sapwood blocks, more advanced in the case of the white-rot fungal strain 3 (S-W), which appeared to be faster growing, especially on European beech. This might be explained by the preference of white-rots for hardwoods compared to softwoods. The calculated FCA values after 7 days of incubation were maximum for the fungal strain 3 (S-W): $84 \%$ for European beech, respectively 52,6\% for Scots pine sapwood and minimum for brown-rot fungal strain 2 (FC1-B): 41,4 \% for European beech, respectively $40,7 \%$ for Scots pine. In the case of brown-rot fungal strain 1 (FC1-W) the FCA values were $60,1 \%$ for European beech and 51,8\% for Scots pine. The surfaces of all control plates were almost completely covered with mycelium by day 42 (FCA 94,7-100\%). All these demonstrated an active fungal attack.

The treatment with Diffusit S (10\%) delayed the fungal growth, but did not stop it. It had minimum effect on the white-rot fungal strain $3(\mathrm{~S}-\mathrm{W})$, for which limited fungal growth was evident for the treated European beech (FCA 9,9\%) and Scots pine sapwood (FCA 7,0 \%) samples after 7 days of incubation (Figure 5). For 
the two brown-rot strains (FC1-W, FC1-B) fungal growth started later (Figure 3, Figure 5), but evolved rapidly, the mycelium covering the whole plates after 42 days of incubation (FCA $97 \%$ - 100 \%), similar to the control samples.

In contrast, the treatment with C-EO (10\%) seemed to be effective as a curative treatment against the brown-rot strain 2 (FC1-B) for both European beech wood and Scots pine sapwood, suppressing fungal growth for the entire testing period of 90 days (Figure 4). However, the treatment was only partially efficient in the case of the brown-rot strain 1 (FC1-W), for which no fungal growth was registered or Scots pine, but some fungal growth was registered for European beech (on 1 of 2 replicates) (Figure 3). The corresponding mean FCA values for FC1-W on C-EO treated European beech samples were $27,3 \%$ after 42 days of incubation and $50 \%$ after 90 days.

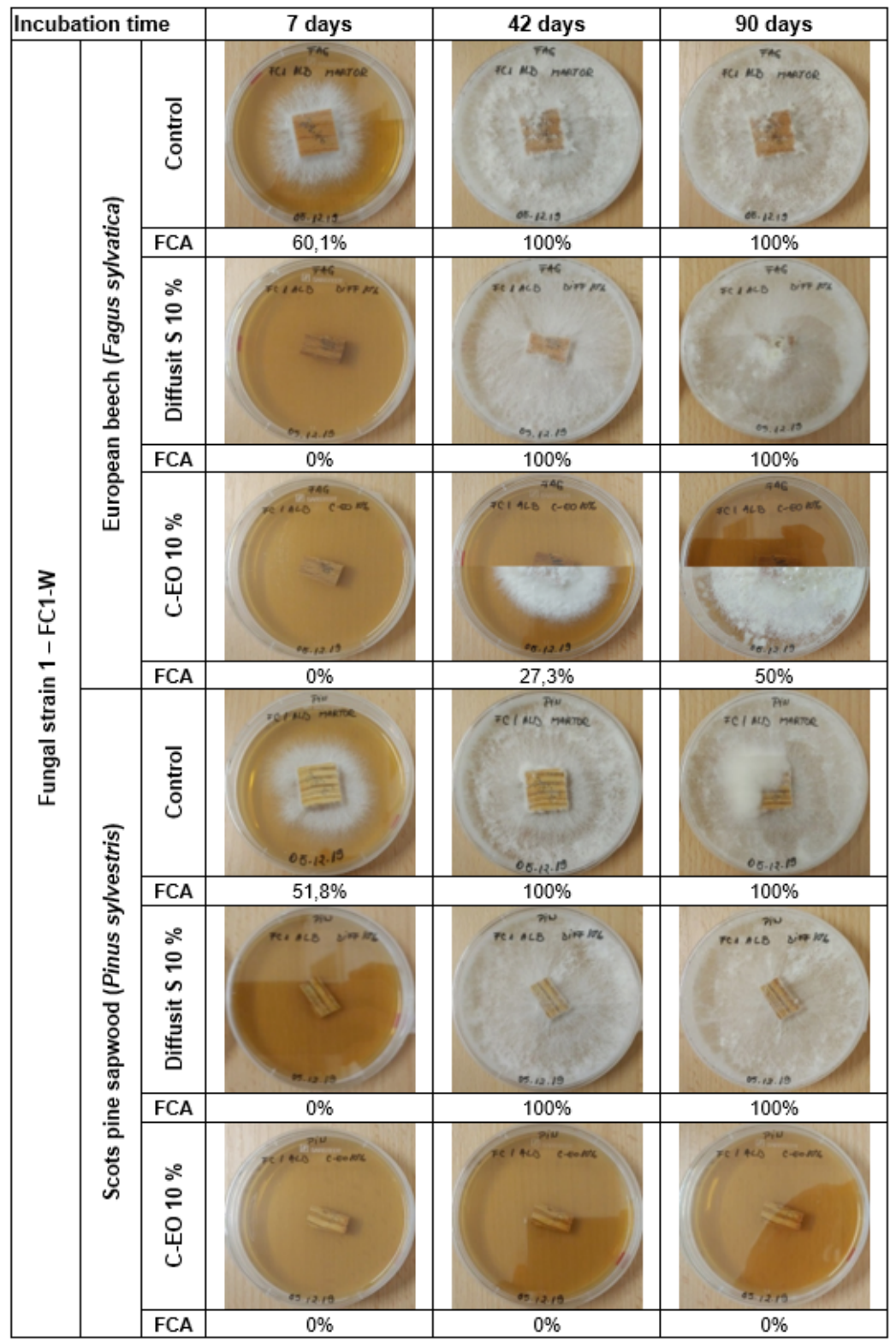

Figure 3: Lab test 2-Comparative efficiency of Diffusit S and C-EO solutions (10\%) in suppressing active decay of European beech and Scots pine sapwood, following controlled infection with the brown-rot fungal strain 1 (FC1-W): evolution of fungal development after 7, 42 and 90 days of incubation; fungal coverage area values (FCA, \%) included;

Note: combined pictures with different upper and bottom halves indicate a different behaviour of the two replicates; FCA values are averages for the two replicates. 


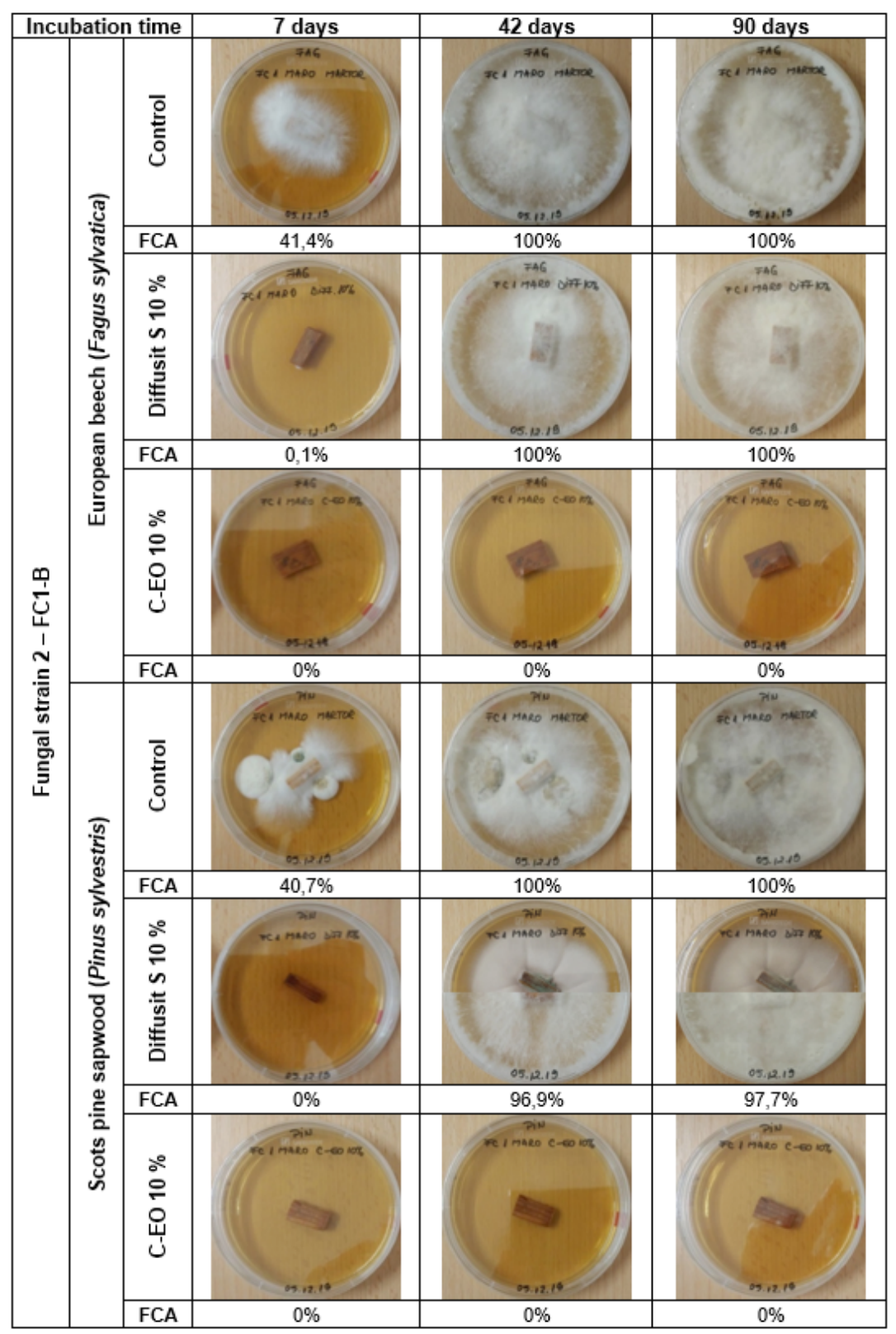

Figure 4: Lab test 2-Comparative efficiency of Diffusit S and C-EO solutions (10\%) in suppressing active decay of European beech and Scots pine sapwood, degraded following controlled infection with the brown-rot fungal strain 2 (FC1-B): evolution of fungal development after 7, 42 and 90 days of incubation; calculated fungal coverage area values (FCA, \%) included;

Note: combined pictures with different upper and bottom halves indicate a different behaviour of the two replicates; FCA values are averages for the two replicates. 


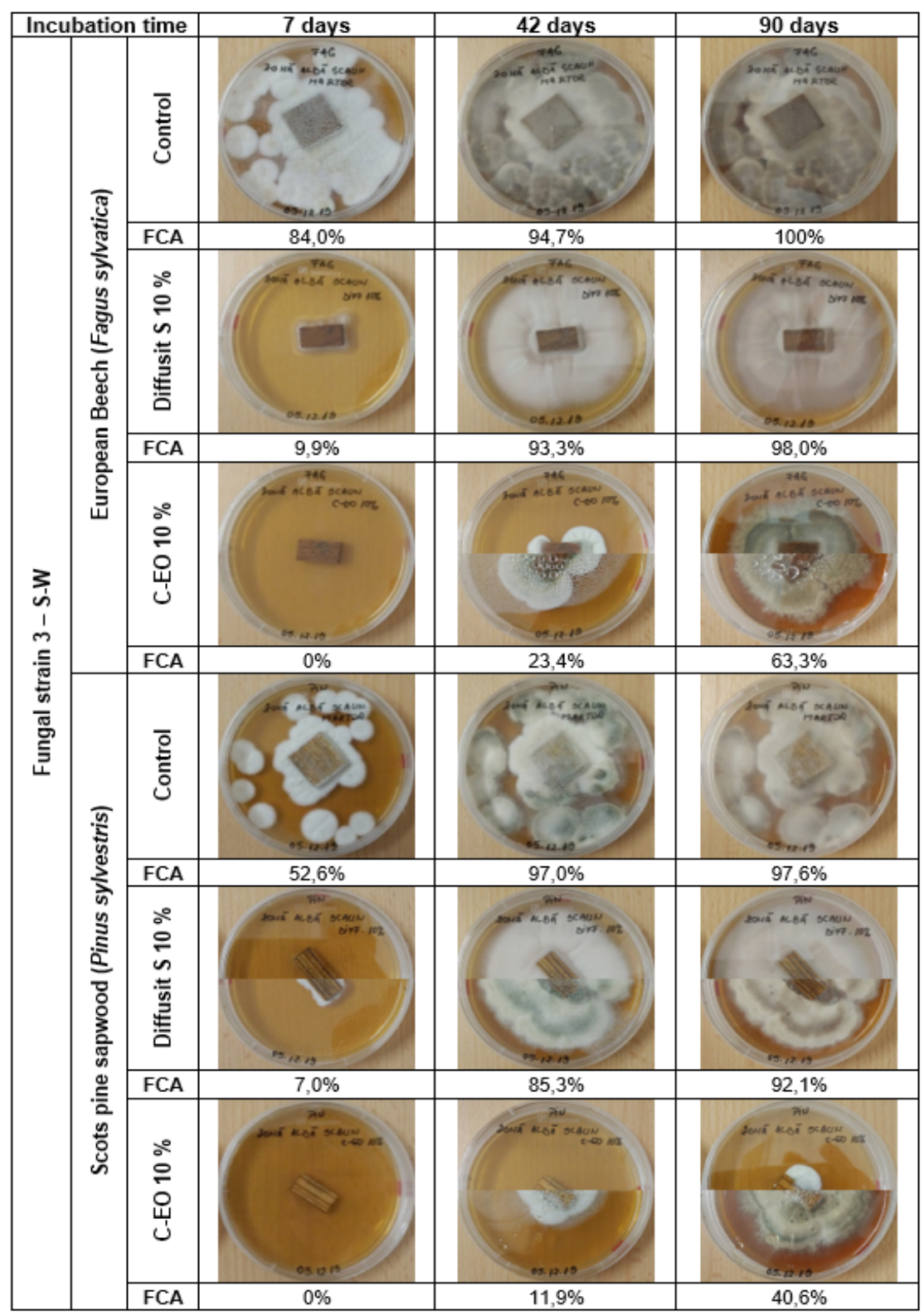

Figure 5: Lab test 2-Comparative efficiency of Diffusit $\mathrm{S}$ and C-EO solutions (10\%) in suppressing active decay of European beech and Scots pine sapwood, degraded following controlled infection with the selective white-rot fungal strain 3 (S-W): evolution of fungal development after 7, 42 and 90 days of incubation; calculated fungal coverage area values (FCA, \%) included;

Note: combined pictures with different upper and bottom halves indicate a different behaviour of the two replicates; FCA values are averages for the two replicates.

In the case of the selective white-rot fungal strain $3(\mathrm{~S}-\mathrm{W})$ the treatment with C-EO could not suppress the fungal attack for none of the two wood species but induced a delay (no fungal growth after 7 days) and then a slower fungal development (Figure 5). European beech wood was more sensitive than Scots pine sapwood to this fungal attack, so that after 42 days of incubation mean FCA values of 23,4 \% were determined for European beech compared to $11,9 \%$ for Scots pine sapwood and those values evolved to $63,3 \%$ and $40,65 \%$, respectively, after 90 days of incubation. These results are not surprising considering the preference of whiterot fungi for hardwoods compared to softwoods (Eaton and Hale 1993, Morris 2011). Also, a reduced efficiency of C-EO against white-rot fungi compared to brown-rots has been previously reported (e.g. Broda 2020, 
Panek et al. 2014, Voda et al. 2003). This can be explained considering that white rot fungi have enzymes capable of degrading the complex poly-phenolic structure of lignin, while the main antifungal active ingredient of C-EO, eugenol, is also a phenol. However, for both wood species, the mycelium development for this fungal strain indicated a slower attack for the samples treated with C-EO compared to those treated with Diffusit S, and a clear differentiation when compared to the untreated controls (FCA 94,7 \% - 97,0 \% after 42 days).

Concluding, all these aspects indicated a positive effect of C-EO as curative treatment for decayed wood with active fungal attack, with an improved efficiency compared to the reference product Diffusit S. However, the efficiency of the applied treatments with both products (C-EO and Diffusit) depended on the type of decay fungus and was influenced by the wood species, so that extended research is still further needed.

Also, it has to be mentioned that in some cases (illustrated by combined pictures in Figure 3, Figure 4 and Figure 5) the emerging fungal growth for the two replicates of a certain type were quite different (e.g. no growth in one replica and significant growth in the other replica). Accordingly, the meaning of the average FCA values, resulting from two samples with a different behaviour, should be considered with care and, certainly, more replicates should be considered in further research to get more relevant results. However, such variability in fungal growth should not be considered as a total surprise, as wood fungal attack and degradation is not an uniform process. For instance, it was proved by microspectroscopy studies that the "apparent slow and asynchronous growth of hyphae in lignocellulosic substrates leads to uneven decay caused by brown rot and white rot fungi even in adjacent wood cells" (Fackler and Schwanninger 2012). Accordingly, it could be considered a non-uniformous decay of the samples prepared in lab conditions by inoculation with the three strains isolated from $\mathrm{CH}$ sites and possibly some variability in the absorption of treating solutions between the two replicates.

\section{Comparative efficiency of C-EO versus diffusit $\mathrm{S}$ and final discussions}

To better highlight the antifungal efficiency of C-EO in comparison with Diffusit $\mathrm{S}$, the calculated percentage indices of reduction of fungal development (IRD - defined in section 2.2.3) were plotted in Figure 6 for the lab test 2 with the three decay fungal strains isolated from cultural heritage).

IRD-abs compares treated wood with untreated control, so that any positive value indicates an antifungal activity, higher values counting for improved efficiency, while a maximum value of $100 \%$ means a total inhibition/stopping of fungal development. IRD-rel compares the antifungal effects of treatments with C-EO and Diffusit $\mathrm{S}$ as reference, so that a null value means similar activity, any positive value indicates a higher antifungal activity of C-EO, the higher the value the better, while a maximum value of $100 \%$ means that C-EO totally inhibited/stopped the fungal growth.

In this respect, the column graphs and data values (IRD-abs) in Figure 6a, Figure $6 \mathrm{~b}$ highlight an improved efficiency of C-EO compared to Diffusit $\mathrm{S}$ in treatments against active decay by the three fungal strains isolated from $\mathrm{CH}$, as well as some differences in efficiency related to the type of fungus and wood species. The non-null IRD-rel values (Figure 6c) varied in the range of 35-100 \%, being influenced by the fungal strain (maximum for the brown rot FC1-B and minimum for the selective white rot S-W) and the wood species (higher for Scots pine sapwood compared to European beech), especially when considering the fungal strain FC1-W (brown rot). 

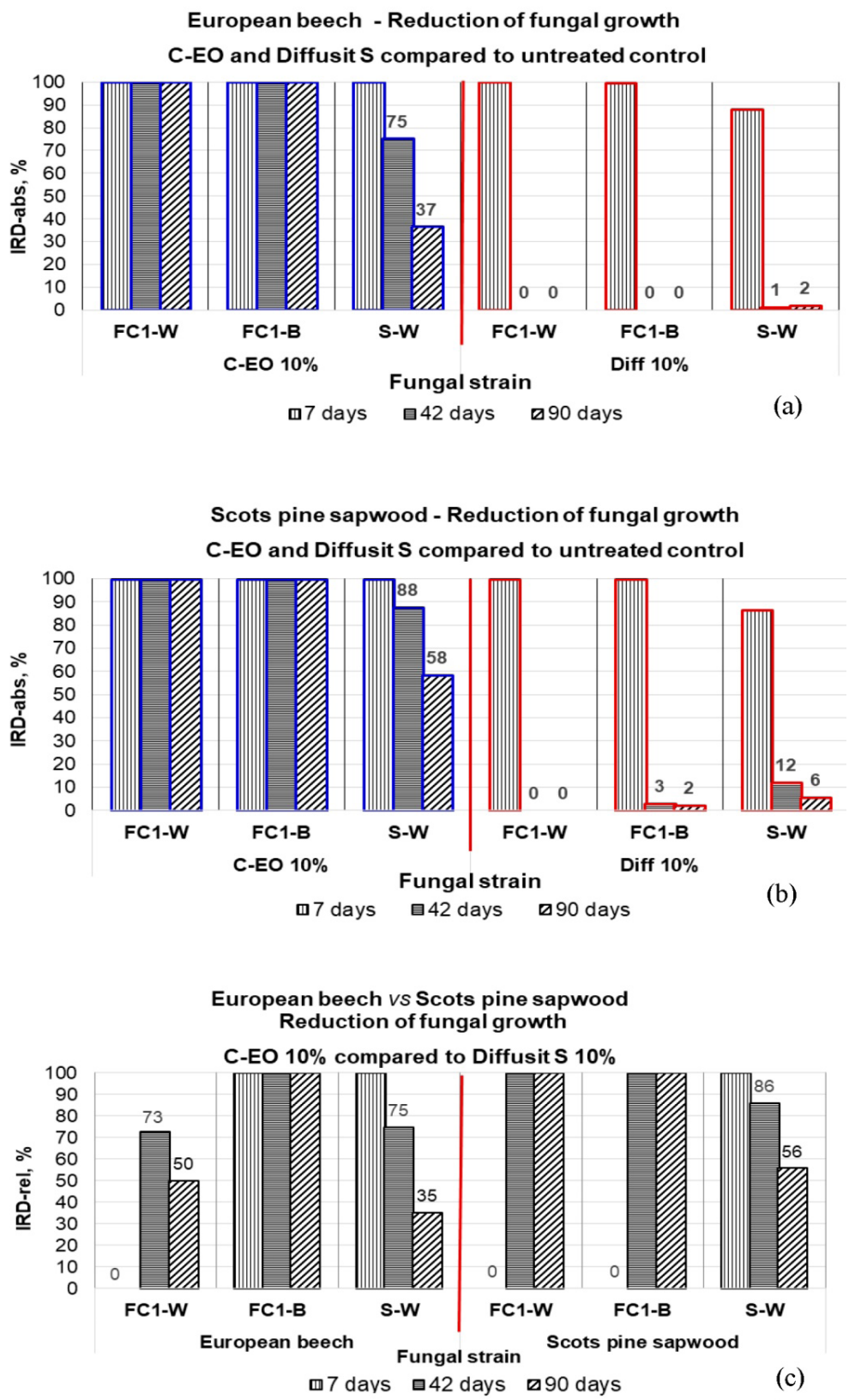

Figure 6: Comparative efficiency of C-EO versus Diffusit $\mathrm{S}$ (solutions $10 \%$ ) in suppressing active decay by three fungal strains (FC1-W, FC1-B, S-W) isolated from $\mathrm{CH}$ (Lab test 2), revealed by the calculated indices of reduction of fungal development: a. IRD-abs for C-EO and Diffusit on European beech wood; b. IRD-abs for C-EO and Diffusit on Scots pine sapwood; c. IRD-rel C-EO compared to Diffusit for European beech and Scots pine sapwood.

\section{CONCLUSIONS}

Biodegradation by mould and decay fungi represents a major risk factor for wood cultural heritage in conditions of high humidity or risk of direct wetting, as for instance in open-air museums.

This research highlighted the potential of clove (Eugenia caryophyllata) essential oil (C-EO) as an alternative antifungal protectant system against moulds and decay fungi for preventive and curative treatments in active conservation of wood artefacts, exposed at risk in unfavourable indoors conditions. 
This resulted from novel dedicated tests on two different types of wood material: $(i)$ new air-infected wood, (ii) wood degraded by controlled infection with three decay fungal strains isolated from cultural heritage sites. These substrates varied in terms of chemical composition as result of decay, with potential influence on their susceptibility to colonisation and decay, or to further biodegradation, as in real conservation practice.

In all these tests, C-EO showed a higher efficiency than a classical boron-based biocide product (Diffusit S), currently employed in the practice of wood conservation and considered as reference in this research.

Based on the current results, alcoholic C-EO solutions of $5 \%-10 \%$ concentration are efficient for preventive treatments against air-borne moulds, while C-EO solutions of $10 \%$ can suppress or delay active attack by decay fungi.

The concentration, application methods and application rates of the C-EO wood protection system should be correlated with the risk and/or aggressiveness of the fungal attack, type of fungi, wood species and further treatments in the conservation schedule.

Alongside efficiency, employment of C-EO in wood conservation practice as an alternative to classical biocide products could offer the advantages of a more eco-sustainable approach and a lower toxicity for the conservators and restorers, but further dedicated research is needed in this area, as well as a thorough evaluation of the complex compatibility issues.

\section{ACKNOWLEDGEMENTS}

This research is part of a $\mathrm{PhD}$ research project underway at the Transilvania University of Braşov (UniT$\mathrm{Bv})$, Romania, supported by a 3 years scholarship from public funds.

The authors also acknowledge the structural founds project PRO-DD (POS-CCE, O.2.2.1, ID 123, SMIS 2637, contract No 11/2009) for providing the infrastructure used in the research process.

We do also express our gratitude to prof Marinela Burada (UniTBv) for assistance in language improvement and to dr Andrew Pitman (Lignia - UK) for his expert advice and corrections of the manuscript.

\section{REFERENCES}

Adamiak, J.; Otlewska, A.; Tafer, H.; Lopandic, K.; Gutarowska, B.; Sterflinger, K.; Pinar, G. 2018. First evaluation of the microbiome of built cultural heritage by using the Ion Torrent next generation sequencing platform. Int Biodeter Biodegr 131: 11-18. https://doi.org/10.1016/j.ibiod.2017.01.040

Alborés, S.; Sanguiñedo, P.; Held, B.H.; Cerdeiras, M.P.; Blanchette, R.A. 2018. Biodiversity and antimicrobial activity of Antarctic fungi from the Fildes Peninsula, King George Island. Sydowia 70: 185-191. https://doi.org/10.12905/0380.sydowia70-2018-0185

Alfieri, P.V.; Garcia, R.; Rosato V.; Correa, M.V. 2016. Biodegradation and biodeterioration of wooden heritage: role of fungal succesion. Int J Conserv Sci 7(3): 607-614. https://ri.conicet.gov.ar/handle/11336/55034

Al-Jaradi, A.; Al-Mahmooli, I.; Janke, R.; Maharachchikumbura, S.; Al-Saady, N.; Al-Sadi, A.M. 2018. Isolation and identification of pathogenic fungi and oomycetes associated with beans and cowpea root diseases in Oman. PeerJ- Microbiology 6: e6064. http://doi.org/10.7717/peerj.6064

Bahmani, M.; Schmidt, O. 2018. Plant essential oils for environment-friendly protection of wood objects against fungi. Maderas-Cienc Tecnol 20(3): 325-332. http://dx.doi.org/10.4067/S0718-221X2018005003301

Bakkali, F.; Averbeck, S.; Averbeck, D.; Idaomar, M. 2008. Biological effects of essential oils - A review. Food Chem Toxicol 46(2): 446-475. https://doi.org/10.1016/j.fct.2007.09.106 
Borrego, S.; Valdes, O.; Vivar, I.; Lavin, P.; Guiamet, P.; Battistoni, P.; Gomez de Saravia, S.; Borges, P. 2012. Essential Oils of Plants as Biocides against Microorganisms Isolated from Cuban and Argentine Documentary Heritage. Int Sch Res Notices Microbiology 2012(1): 826786. https://doi.org/10.5402/2012/826786

Brischke, C.; Alfredsen, G. 2020. Wood-water relationships and their role for wood susceptibility to fungal decay. Appl Microbiol Biotechnol 104(3): 3781-3795. https://doi.org/10.1007/s00253-020-10479-1

Brischke, C.; Welzbacher, C.R.; Gellerich, A.; Bollmus, S.; Humar, M.; Schneiding, W.; Alfredsen, G.; Van Acker, J.; De Windt, I. 2014. Wood natural durability testing under laboratory conditions: results from a round-robin test. Eur J Wood Prod 72(1): 129-133. https://doi.org/10.1007/s00107-013-0764-6

Broda, M. 2020. Natural Compounds for Wood Protection against Fungi - A Review. Molecules 25(15): 3538. https://doi.org/10.3390/molecules25153538

Eaton, R.A.; Hale, M.D.C. 1993. Wood: decay, pests, and protection (1st edition). Chapman \& Hall: London, UK.

Fackler, K.; Stevanic, J.S.; Ters, T.; Hinterstoisserc, B.; Schwanninger, M.; Salmén, L. 2010. Localisation and characterisation of incipient brown-rot decay within spruce wood cell walls using FT-IR imaging microscopy. Enzyme Microbial Technol 47(6): 257-267. https://doi.org/10.1016/j.enzmictec.2010.07.009

Fackler, K.; Schwanninger, M. 2012. How spectroscopy and microspectroscopy of degraded wood contribute to understand fungal wood decay. Appl Microbiol Biotechnol 96: 587-599. https://doi.org/10.1007/s00253-012-4369-5

Hiscox, J.; O'Leary, J.; Boddy, L. 2018. Fungus wars: basidiomycete battles in wood decay. Stud Mycol 89: 117-124. https://doi.org/10.1016/j.simyco.2018.02.003

ImageJ. 2020. Why Open Source?.https://imagej.net/Open_source

Jeong, S.H.; Lee, H.J.; Kim, D.W.; Chung, Y.J. 2018. New biocide for eco-friendly biofilm removal on outdoor stone monuments. Int Biodeter Biodegr 131: 19-28. https://doi.org/10.1016/j.ibiod.2017.03.004

Jönsson, M.T.; Edman, M.; Jonsson, B.G. 2008. Colonization and extinction patterns of wood-decaying fungi in a boreal old-growth Picea abies forest. J Ecol 96(5): 1065-1075. https://doi.org/10.1111/j.13652745.2008.01411.x

Kakakhel, M.A.; Wu, F.; Gu, J.D.; Fenga, H.; Shah, K.; Wang, W. 2019. Controlling biodeterioration of cultural heritage objects with biocides: A review. Int Biodeter Biodegr 143: 104721. https://doi.org/10.1016/j.ibiod.2019.104721

Kim, M.J.; Shin, H.K.; Choi, Y.S.; Kim, G.C.; Kim, G.H. 2016. An aeromycological study of various wooden Cultural Heritages in Korea. J Cult Herit 17: 123-130. https://doi.org/10.1016/j.culher.2015.05.001

Lee, H.J.; Jeong, S.H.; Chung, Y.J. 2018. Wood injury characteristics of fungi isolated from printing wood blocks of the Tripitaka Koreana in the Haeinsa Temple at Hapcheon, Republic of Korea. Int Biodeter Biodegr 131: 29-39. http://dx.doi.org/10.1016/j.ibiod.2017.03.019

Lie, S.K.; Vestøl, G.I.; Høibø, O.; Gobakken, L.R. 2019a. Surface mould growth on wooden claddings effects of transient wetting, relative humidity, temperature and material properties. Wood Mater Sci Eng 14(3): 129-141. http://dx.doi.org/10.1080/17480272.2018.1424239

Lie, S.K.; Vestøl, G.I.; Høibø, O.; Gobakken, L.R. 2019b. Surface mould growth on wood: a comparison of laboratory screening tests and outdoor performance. Eur J Wood Prod 77: 1137-1150. https://doi.org/10.1007/s00107-019-01444-5

Lis-Balchin, M. 2006. Chapter 7. The safety issue in aromatherapy. In: Aromatherapy Science. Pharmaceutical Press: London, UK. ISBN 0-85369 578 4. http://www.pharmpress.com/files/docs/aromascich07.pdf 
Matusiak, K.; Machnowski, W.; Wrzosek, H.; Polak, J.; Rajkowska, K.; Smigielski, K.; Kunicka-Styczynska, A.; Gutarowska, B. 2018. Application of Cinnamomum zeylanicum essential oil in vapour phase for heritage textiles disinfection. Int Biodeter Biodegr 131: 88-96. http://dx.doi.org/10.1016/j. ibiod.2017.02.011

Morris, P.I. 2011. Chapter 33. Microbial degradation of wood. In: Uhling's corrosion Handbook. Winston, R. R. (Eds), Wiley Online Library: Hoboken, New Jersey, 461-468. https://doi.org/10.1002/9780470872864. ch33

Ottosson, E.; Nordén, J.; Dahlberg, A.; Edman, M.; Jönsson, M.; Larsson, K.H.; Olsson, J.; Penttilä, R.; Stenlid, J.; Ovaskainen, O. 2014. Species associations during the succession of wood-inhabiting fungal communities. Fungal Ecol 11: 17-28. https://doi.org/10.1016/j.funeco.2014.03.003

Pandey, K.K.; Pitman, A.J. 2003. FTIR studies of the changes in wood chemistry following decay by brown-rot and white-rot fungi. Int Biodeter Biodegr 52(3): 151-160. https://doi.org/10.1016/S09648305(03)00052-0

Panek, M.; Reinprecht, L.; Hulla, M. 2014. Ten essential oils for beech wood protection - efficacy against wood-destroying fungi and moulds, and effect on wood discoloration. Bioresources 9 (3): 5588-5603. http://dx.doi.org/10.15376/biores.9.3.5588-5603

Pietrzaka, K.; Otlewska, A.; Danielewicz, D.; Dybka, K.; Pangallo, D.; Kraková, L.; Puskárová, A.; Bucková, M.; Scholtz, V.; Durovic, M.; Surma-Slusarska, B.; Demnerová, K.; Gutarowska, B. 2017. Disinfection of archival documents using thyme essential oil, silver nanoparticles misting and low temperature plasma. J Cult Herit 24: 69-77. http://dx.doi.org/10.1016/j.culher.2016.10.011

Pop, D.M.; Timar, M.C; Beldean, E.C.; Varodi, A.M. 2020. Combined testing approach to evaluate the antifungal efficiency of clove (Eugenia caryophyllata) essential oil for potential application in wood conservation. Bioresources 15(4): 9474-9489. http://dx.doi.org/10.15376/biores.15.4.9474-9489

Reinprecht, L. 2010. Chapter 5. Fungicides for Wood Protection - World Viewpoint and Evaluation/Testing in Slovakia. In: Fungicides. Carisse, O. (Eds), ISBN: 978-953-307-266-1. InTech. http://www.intechopen.com/books/fungicides/fungicides-for-wood-protection-world-viewpoint-and-evaluation-testing-in-slovakia

Reinprecht, L.; Pop, D.M.; Vidholdová, Z.; Timar, M.C. 2019. Anti-decay potential of five essential oils against the wood-decaying fungi Serpula lacrymans and Trametes versicolor. Acta Fac Xylologiae 61(2): 63-72. http://dx.doi.org/10.17423/afx.2019.61.2.06

Reinprecht, L.; Vidholdová, Z. 2017. Growth inhibition of moulds on wood surfaces in presence of nano $-\mathrm{ZnO}$ and its combinations with polyacrylate and essential oils. Wood Res 62 (1): 37-44. http://www.woodresearch.sk/wr/201701/04.pdf

Sabatini, L.; Sisti, M.; Campana, R. 2018. Evaluation of fungal community involved in the bioderioration process of wooden artworks and canvases in Montefeltro area (Marche, Italy). Microbiol Res 207: 203-210. https://doi.org/10.1016/j.micres.2017.12.003

Sterflinger, K. 2010. Fungi: Their role in deterioration of cultural heritage. Fungal Biol Rev 24(1-2): 47-55. https://doi.org/10.1016/j.fbr.2010.03.003

Stupar, M.; Grbić, M, Lj.; Džamić, A.; Unković, N.; Ristić, M.; Jelikić, A.; Vukojević, J. 2014. Antifungal activity of selected essential oils and biocide benzalkonium chloride against the fungi isolated from cultural heritage objects. S Afr J Bot 93: 118-124. http://dx.doi.org/10.1016/j.sajb.2014.03.016

Ujor, V.C.; Adukwu, E.C.; Okonkwo, C.C. 2018. Fungal wars: The underlying molecular repertoires of combating mycelia. Fungal Biol 122(4): 191-202. https://doi.org/10.1016/j.funbio.2018.01.001

Varnai, V.M.; Macan, J.; Ljubicic, A.; Prester, Lj.; Kanceljak Macan, B.2011. Upper respiratory impairment in restorers of cultural heritage. Occup Med 61(1): 45-52. https://doi.org/10.1093/occmed/kqq170 
Voda, K.; Boh, B.; Vrtacnik, M.; Pohleven, F. 2003. Effect of the antifungal activity of oxygenated aromatic essential oil compounds on the white-rot Trametes versicolor and the brown-rot Coniophora puteana. Int Biodeter Biodegr 51(1): 51-59. https://doi.org/10.1016/S0964-8305(02)00075-6

Wang, S-Y.; Chen, P-F.; Chang, S-T. 2005. Antifungal activities of essential oils and their constituents from indigenous cinnamon (Cinnamomum osmophloeum) leaves against wood decay fungi. Bioresour Technol 96(7): 813-818. https://doi.org/10.1016/j.biortech.2004.07.010

Wu, P.C.; Chou, C.L. 2018. Utilisation of essential oils for wooden sculpture conservation at Juming Museum. J Inst Conserv 41(3): 235-245. https://doi.org/10.1080/19455224.2018.1510424

Xie, Y.; Wang, Z.; Huang, Q.; Zhang, D. 2017. Antifungal activity of several essential oils and major components against wood-rot fungi. Ind Crops Prod 108: 278-285. https://doi.org/10.1016/j.indcrop.2017.06.041

Yang, V.W.; Clausen, C.A. 2007. Antifungal effect of essential oils on southern yellow pine. Int Biodeter Biodegr 59(4): 302-306. https://doi.org/10.1016/j.ibiod.2006.09.004

Zhang, F.; Li, L.; Sun, M.; Hu, C.; Zhang, Z.; Liu, Z.; Shao, H.; Xi, G.; Pan, J. 2019. Fungal community analyses of a pirogue from the Tang Dynasty in the National Maritime Museum of China. Appl Sci 9(19): 4129. https://doi.org/10.3390/app9194129

Zhang, Z.; Yang, T.; Na, M.; Wang, Y.; Li, G.; Wang, L.; Xie, Y. 2016. Antifungal activity of monoterpenes against wood white-rot fungi. Int Biodeter Biodegr 106: 157-160. https://doi.org/10.1016/j.ibiod.2015.10.018

Zyani, M.; Mortabit, D.; El Abed, S.; Remmal, A.; Koraichi, S.I. 2011. Antifungal activity of Five Plant Essential Oils against wood decay fungi isolated from an old house at the Medina of Fez. Int Res $J$ Microbiol 2(3): 104-108. https://www.interesjournals.org/articles/antifungal-activity-of-five-plant-essential-oils-against-wood-decay-fungi-isolated-from-an-old-house-at-themedina-of-fez.pdf 